\title{
Synthesis and Characterization of Bifunctional $\alpha-\mathrm{Fe}_{2} \mathrm{O}_{3}-\mathrm{Ag}$ Nanoparticles
}

\author{
Alvaro Ruíz-Baltazar, ${ }^{1}$ Simón Yobanny Reyes-López, ${ }^{2}$ Rodrigo Esparza, ${ }^{1}$ Miriam Estévez, \\ Ángel Hernández-Martínez, ${ }^{1}$ Gerardo Rosas, ${ }^{3}$ and Ramiro Pérez ${ }^{1}$ \\ ${ }^{1}$ Centro de Físisca Aplicada y Tecnología Avanzada, Universidad Nacional Autónoma de México, \\ Boulevard Juriquilla 3001, 76230 Santiago de Querétaro, QRO, Mexico \\ ${ }^{2}$ Instituto de Ciencias Biomédicas, Universidad Autónoma de Ciudad Juárez, Envolvente del PRONAF y Estocolmo s/n, \\ 32300 Ciudad Juárez, CHIH, Mexico \\ ${ }^{3}$ Instituto de Investigaciones Metalúrgicas, UMSNH, Edificio U, Ciudad Universitaria, 58000 Morelia, MICH, Mexico
}

Correspondence should be addressed to Simón Yobanny Reyes-López; simon.reyes@uacj.mx

Received 12 July 2015; Accepted 20 September 2015

Academic Editor: Mohindar S. Seehra

Copyright (C) 2015 Alvaro Ruíz-Baltazar et al. This is an open access article distributed under the Creative Commons Attribution License, which permits unrestricted use, distribution, and reproduction in any medium, provided the original work is properly cited.

The synthesis of $\alpha-\mathrm{Fe}_{2} \mathrm{O}_{3}$-Ag bimetallic nanoparticles using a novel and simplified route is presented in this work. These hybrid nanoparticles were produced using a modification of the chemical reduction method by sodium borohydride $\left(\mathrm{NaBH}_{4}\right)$. $\mathrm{Fe}(\mathrm{III})$ chloride hexahydrate $\left(\mathrm{FeCl}_{3} \cdot 6 \mathrm{H}_{2} \mathrm{O}\right)$ and silver nitrate $\left(\mathrm{AgNO}_{3}\right)$ as precursors were employed. Particles with semispherical morphology and dumbbell configuration were observed. High-resolution transmission electron microscopy (HRTEM) technique reveals the structure of the dumbbell-like $\alpha-\mathrm{Fe}_{2} \mathrm{O}_{3}-\mathrm{Ag}$ nanoparticles. Some theoretical models further confirm the formation of the $\alpha-\mathrm{Fe}_{2} \mathrm{O}_{3}$-Ag structures. Analysis by cyclic voltammetry reveals an interesting catalytic behavior which is associated with the combination of the individual properties of the $\mathrm{Ag}$ and $\alpha-\mathrm{Fe}_{2} \mathrm{O}_{3}$ nanoparticles.

\section{Introduction}

Bimetallic nanoparticles with dumbbell-like heterostructures have recently attracted increasing attention on these nanoparticles exhibiting different physical and chemical properties and an interesting interfacial interaction between two coexisting materials. This property offers potential applications in the fields of physics, biotechnology, chemistry, materials science, biology, and catalysis [1-3]. In particular, the bimetallic $\alpha-\mathrm{Fe}_{2} \mathrm{O}_{3}-\mathrm{Ag}$ dumbbell-like nanoparticles have enhanced physical-chemical properties, since the Ag nanoparticles present an excellent catalytic activity, antibacterial effect, and a significant biocompatibility [4-7]. On the other hand, $\alpha$ $\mathrm{Fe}_{2} \mathrm{O}_{3}$ possess magnetic properties. In this sense, hybrid $\alpha-\mathrm{Fe}_{2} \mathrm{O}_{3}-\mathrm{Ag}$ nanoparticles represent a nanostructure suitable for drug delivery, phototherapy heterogeneous catalysis, and biosensors among others [8-11]. Consequently, research of new synthesis routes for bimetallic nanoparticles is fundamental in the development of nanotechnology [1214]. Under this perspective, the possibility to synthesize new nanostructures by mixing noble metals and magnetic nanoparticles offers a wide range of future applications. For this reason, the aim of this research is to present a novel and simplified synthesis route to obtain $\alpha-\mathrm{Fe}_{2} \mathrm{O}_{3}-\mathrm{Ag}$ dumbbell-like nanostructures. This procedure is based on the modification of the chemical reduction method [15], which is carried out at room temperature and the $\mathrm{pH}$ of the aqueous solution is not considered. Factors such as the quantities of metallic precursors and the amount of surfactant agent used in the synthesis process are important for determining the growth of the $\alpha-\mathrm{Fe}_{2} \mathrm{O}_{3}$ - $\mathrm{Ag}$ bimetallic nanoparticles $[10,16]$. In order to characterize the dumbbell or heterodimers nanostructures, techniques of transmission electron microscopy (TEM), Raman spectroscopy (RMN), and cyclic voltammetry $(\mathrm{CV})$ were employed. 


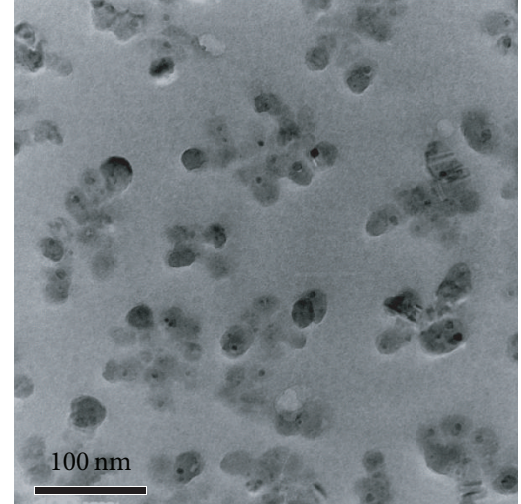

(a)

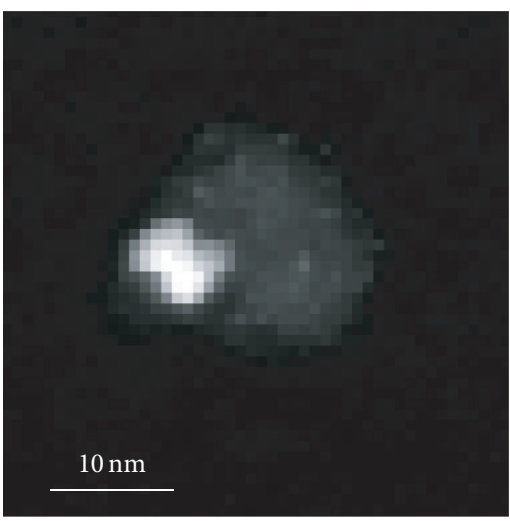

(c)

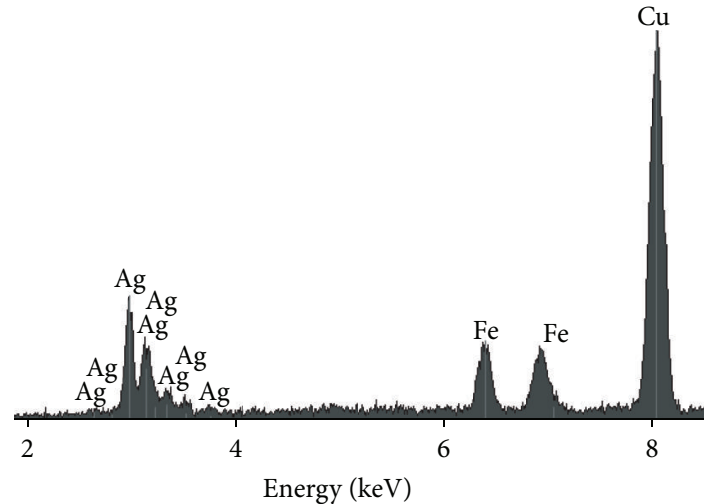

(b)

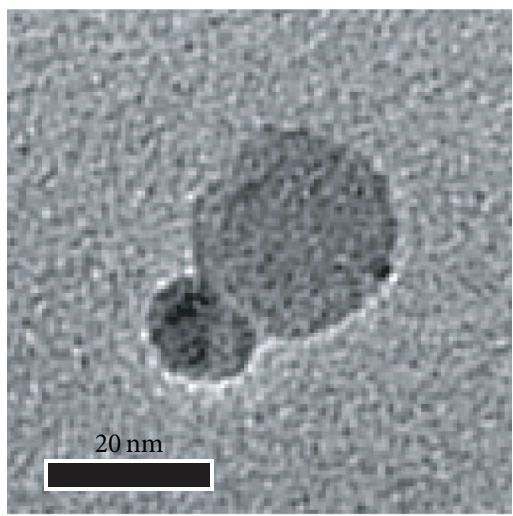

(d)

Figure 1: (a) TEM image of $\alpha$ - $\mathrm{Fe}_{2} \mathrm{O}_{3}$-Ag dumbbell-like nanoparticles, (b) EDS chemical analysis (c) Z-contrast image (HAADF), and (d) bright field TEM image of an individual $\alpha-\mathrm{Fe}_{2} \mathrm{O}_{3}-\mathrm{Ag}$ nanoheterodimers.

\section{Materials and Methods}

The $\alpha-\mathrm{Fe}_{2} \mathrm{O}_{3}-\mathrm{Ag}$ dumbbell nanoparticles were produced using a modification of the chemical reduction method [15]. First, the $\alpha-\mathrm{Fe}_{2} \mathrm{O}_{3}$ nanoparticles were obtained by the reduction of $\mathrm{Fe}(\mathrm{III})$ chloride hexahydrate $(0.01 \mathrm{M})$ with sodium borohydride $\mathrm{NaBH}_{4}(0.02 \mathrm{M})$ and stabilized using polyvinylpyrrolidone (PVP) at constant concentration of $0.5 \mathrm{M}$. The $\alpha-\mathrm{Fe}_{2} \mathrm{O}_{3}$ nanoparticles were stirred magnetically at $600 \mathrm{rpm}$ for 10 minutes. Finally, a solutions of $\mathrm{AgNO}_{3}$ $(0.02 \mathrm{M})$ was added dropwise to the $\alpha-\mathrm{Fe}_{2} \mathrm{O}_{3}$ nanoparticles. This process was carried out at room temperature. For the determination of the electrochemical behavior, a PGSTAT Autolab 302 Potentiostat/Galvanostat (Metrohm) was used. In this procedure, $30 \mu \mathrm{L}$ of $\alpha-\mathrm{Fe}_{2} \mathrm{O}_{3}$-Ag nanoparticles in solution was mixed with $5 \mathrm{mg}$ of carbon. Subsequently, ethanol and Nafion were added to the bimetallic nanoparticles. For the structural characterization of $\alpha-\mathrm{Fe}_{2} \mathrm{O}_{3}-\mathrm{Ag}$ dumbbell nanoparticles, a transmission electron microscopy TEM (Phillips Tecnai F-20) was employed to observe the morphology and sizes of iron-silver nanoparticles.

\section{Results and Discussion}

Figure 1(a) shows a bright field TEM image of the nanostructures obtained by chemical reduction. This image shows dispersed heterodimers or dumbbell-like nanostructures. This kind of structures presents a typical configuration which consists of a nanoparticle with known composition and size and which is attached to another particle whose composition is different and its size is generally smaller. In order to probe that two different elements are present in this heterodimers nanostructures, Figure 1(b) reveals the chemical composition of the bimetallic structures obtained by EDS technique. Figure 1 (c) present a $Z$-contrast image obtained by high angle angular dark field (HAADF), which illustrates that the particles with smaller size and higher contrast are associated with the Ag, due to the fact that this element has a higher atomic number $(Z)$ in relation to the iron. Ag nanoparticles show higher contrasts region (lighter). Consequently, darker region corresponds to nanoparticle with low $Z(\mathrm{Fe})$. In this sense, Figure 1(d) shows a bright field TEM image of an individual nanostructure where $\mathrm{Ag}$ nanoparticles with higher $Z$ exhibit darker contrast. Also, as will be discussed later by highresolution transmission electron microscopy HRTEM technique and Raman spectroscopy, the nature of the Fe structure present in the heterodimer will be determined.

To verify the Fe nanostructure present in the HRTEM analysis that was carried out, Figure 2(a) reveals the $d$-spacing related to the heterodimer, in which we can observe distances of $0.235,0.236$, and $0.198 \mathrm{~nm}$ corresponding to the planes 


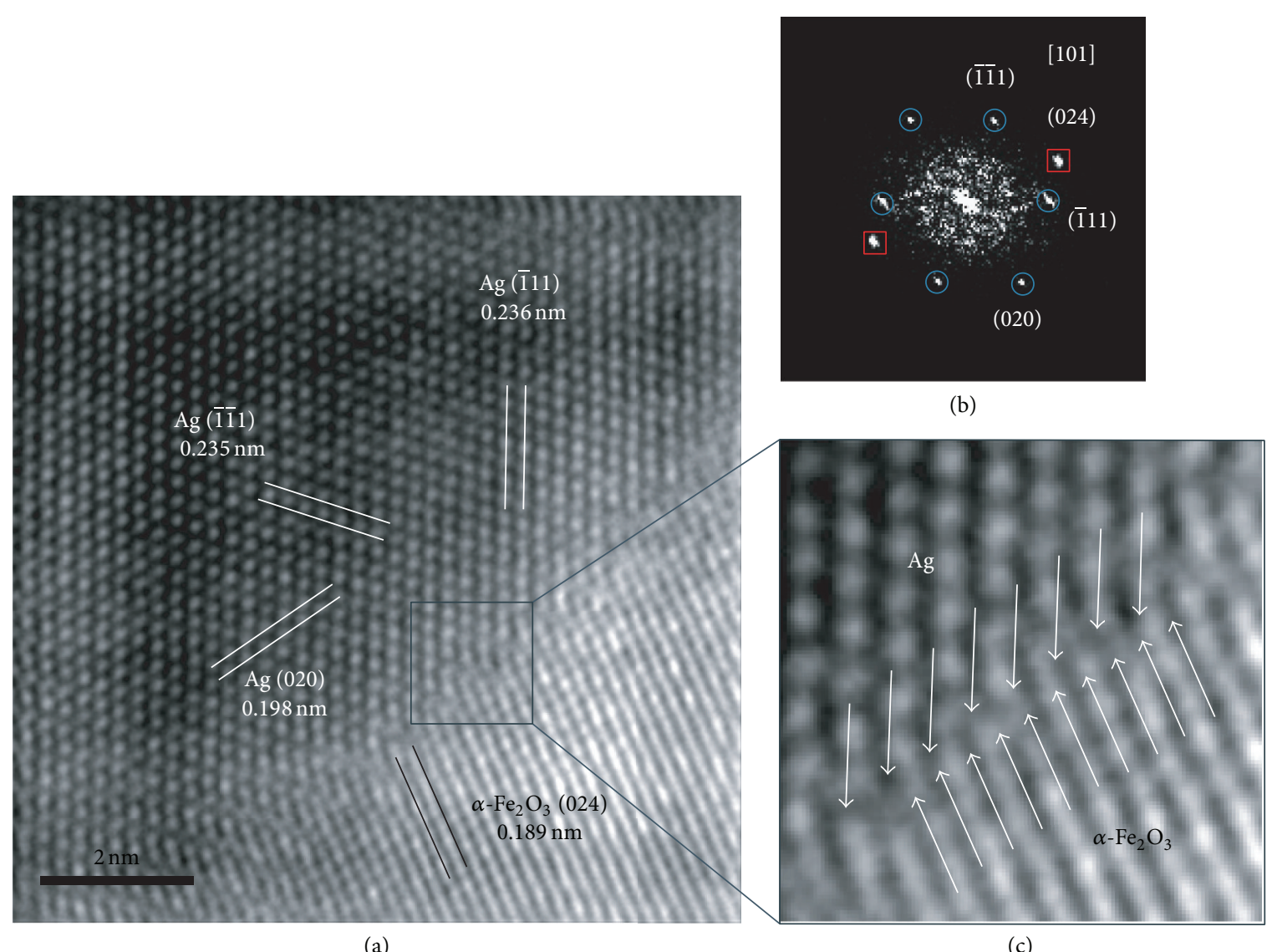

(a)

(c)

Figure 2: (a) HREM image of the $\alpha$ - $\mathrm{Fe}_{2} \mathrm{O}_{3}$-Ag interface, (b) FFT of the HREM image associated with the $\alpha$-Fe $\mathrm{O}_{3}$-Ag bimetallic nanoparticles, and (c) HREM filtered image of dumbbell-like particle.

( $\overline{1} \overline{1} 1)$, (111), and (020) of Ag, respectively (JCPDF \#040783). Additionally, an interplanar distance of $0.189 \mathrm{~nm}$ associated with the $\alpha-\mathrm{Fe}_{2} \mathrm{O}_{3}$ (JCPDF \#33-0664) was observed. Figure 2(b) illustrates the FFT of the $\alpha-\mathrm{Fe}_{2} \mathrm{O}_{3}-\mathrm{Ag}$ system. Also, Figures 2(c) and 2(d) show in detail the interface of the heterodimer, where the presence of both entities is confirmed. This result suggests that the Fe nanoparticles were oxidized. Some reports indicate that the iron nanoparticles can be oxidized by many factors as $\mathrm{pH}$ of aqueous solution and oxidative etching among others $[10,16]$. In particular, in this synthesis process, the $\mathrm{pH}$ of the aqueous solution was constant; therefore, it can be deduced that oxidative species such as oxygen, $\mathrm{Fe}(\mathrm{III})$ in solution, and corrosive ions as chlorides present during the chemical synthesis favor the oxidation process.

Under this perspective, it is important to establish the structure and crystallinity of the nanoparticles. Ag and $\alpha$ $\mathrm{Fe}_{2} \mathrm{O}_{3}-\mathrm{Ag}$ nanoparticles have a cubic FCC structures. In this sense, Figure 3(a) describes a simulation model of the dumbbell-like nanostructure. The Ag nanoparticle modelling (Inodecahedron) has an average size of $7 \mathrm{~nm}$ according to the experimental Ag nanoparticle observed by TEM and high angle annular dark field (HAADF) images, while $\alpha-\mathrm{Fe}_{2} \mathrm{O}_{3}-\mathrm{Ag}$ structures show an average diameter of $20 \mathrm{~nm}$. In order to verify the structures observed by HRTEM images, a simulated
TEM image was constructed from the proposed model (Figure 3(b)). The method to obtain the theoretical images (HRTEM) is based on the multislice approach of electron diffraction dynamical theory [17]. This simulated image presents a close similarity to the experimental HRTEM image. Hence, this model describes accurately the $\alpha-\mathrm{Fe}_{2} \mathrm{O}_{3}$ $\mathrm{Ag}$ heterodimers formation. The axis zone used to the TEM image simulation was [201]. Figure 3(c) describes in detail the simulated interface of the $\alpha-\mathrm{Fe}_{2} \mathrm{O}_{3}$ and $\mathrm{Ag}$ structures. This image exhibits a great similarity with the experimental HRTEM image shown in Figure 2(c). Therefore, the proposed models and simulated images confirm and support the characterization carried out by the HRTEM technique, which indicates the presence of $\alpha-\mathrm{Fe}_{2} \mathrm{O}_{3}$ and $\mathrm{Ag}$ nanostructures.

Nevertheless, the iron species such as the maghemite $(\gamma$ $\left.\mathrm{Fe}_{2} \mathrm{O}_{3}\right)$ and hematite $\left(\alpha-\mathrm{Fe}_{2} \mathrm{O}_{3}\right)$ are very similar from the point of view of their electronic configuration, lattice parameter, and $d$-spacing [17-19]. For this reason, it is important to accurately set the kind of iron oxide observed. Some reports indicate that by XRD technique it is possible to establish only the structural differences between two iron oxides [20-22]. In this regard, Raman spectroscopy can provide clear assignment of the iron oxide polymorphs through the observation of the phonon modes. The iron oxides species exhibit distinct Raman signatures; therefore, it is possible to take advantage 


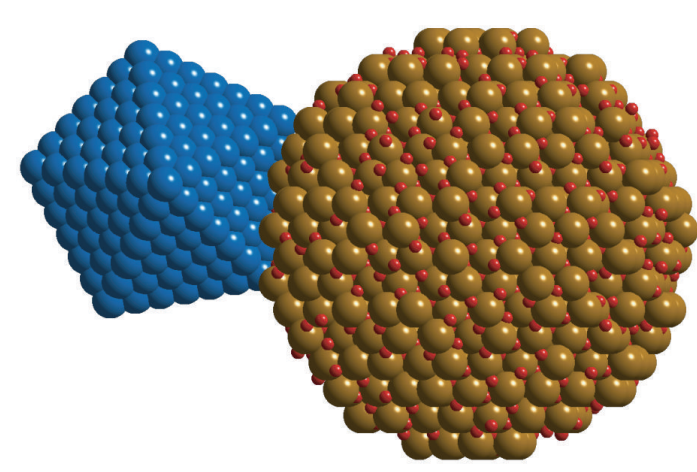

(a)

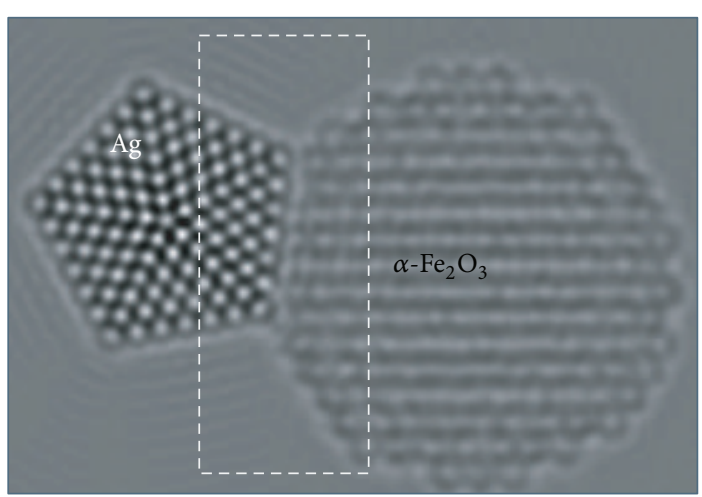

(b)

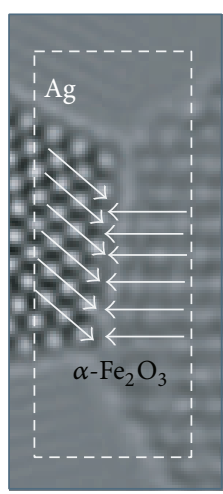

(c)

Figure 3: (a) Simulation model of the dumbbell-like $\alpha-\mathrm{Fe}_{2} \mathrm{O}_{3}$-Ag nanostructure, (b) simulated bright field image, and (c) simulated image from the interface of $\alpha-\mathrm{Fe}_{2} \mathrm{O}_{3}$-Ag.

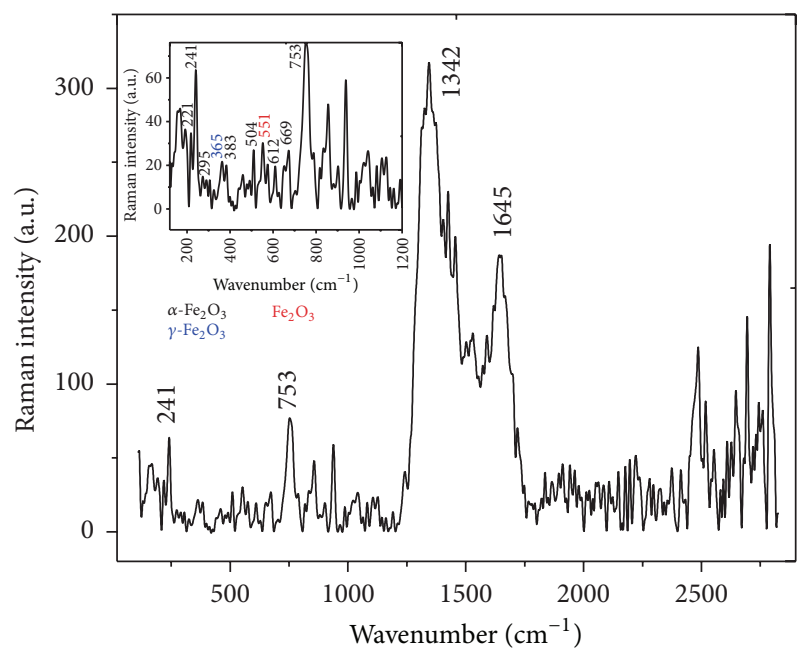

FIgURE 4: Raman spectrum of the $\alpha-\mathrm{Fe}_{2} \mathrm{O}_{3}$-Ag bimetallic system.

of the so-called phonon confinement effects to confirm the oxide present in the sample [23]. In order to demonstrate accurately the type of oxide present in the system, a Raman spectrum of dumbbell nanoparticles is presented in Figure 4.

In these Raman spectra, typical intensities from the hematite structure located at $221 \mathrm{~cm}^{-1}(\mathrm{Alg}), 241 \mathrm{~cm}^{-1}(\mathrm{Eg})$, $295 \mathrm{~cm}^{-1}$ (Eg), and $504(\mathrm{Alg})$ are observed. However, two bands situated at 365 and $551 \mathrm{~cm}^{-1}$ are attributed to maghemite and magnetite, respectively [23]. These bands account for only minority phases, with hematite being the predominant phase, thus confirming the results obtained by HRTEM. Complementarily, the presence of the Ag nanoparticles is demonstrated by the bands situated at 1342 and $1645 \mathrm{~cm}^{-1}$ $[20,21]$.

The formation of this kind of nanostructures can be discussed from the point of view of the solubility, since in general terms these elements are immiscible in the solid state, promoting the dumbbell configuration. In addition, the nucleation rate takes preponderant role in the formation of the $\mathrm{Fe}_{2} \mathrm{O}_{3}$-Ag system because $\mathrm{Fe}$ nanoparticles, previously formed, offer nucleation sites for forming Ag nanoparticles through a heterogeneous nucleation. Thermodynamically, Ag solution atoms nucleate in regions where the energy barrier is lower, in this case in the $\alpha-\mathrm{Fe}_{2} \mathrm{O}_{3}$ nanoparticles. To expand the discussion regarding the factors that involved the growing of these nanostructures, the surface charges associated with the active sites of the nanoparticles should be considered [18]. Based on the fact that the particle size and structure type determine the compensation charge in the nanoparticles surface, it can be deduced that mainly the size of decahedral Ag nanoparticles would influence the charge compensation and hence the formation of $\mathrm{Fe}_{2} \mathrm{O}_{3}$ heterostructures [24], due the fact that the decahedral nanoparticles exhibit greater reactivity. In this regard, some studies have reported these structures as a function of the $\alpha-\mathrm{Fe}_{2} \mathrm{O}_{3}$ size/size $\mathrm{Ag}$ seed ratio $[22,23]$. It is important to highlight the synthesis methodology presented in this research since it offers a simple route for obtaining controlled bimetallic nanostructures. This synthesis is carried out at room temperature while some other methodologies involve temperature $\left(\sim 400^{\circ} \mathrm{C}\right)[22,24-26]$.

In order to establish a reference parameter regarding the electrochemical behavior of the bimetallic system $\left(\alpha-\mathrm{Fe}_{2} \mathrm{O}_{3}\right.$ $\mathrm{Ag}$ ) and $\mathrm{Ag}$ nanoparticles, Figure 5 shows the cyclic voltammogram corresponding to the bimetallic and monometallic nanoparticles. It can be seen that in the case of bimetallic nanoparticles there is an increase in the current density of the redox processes involved in comparison with the monometallic nanoparticles. Additionally, $\alpha-\mathrm{Fe}_{2} \mathrm{O}_{3}-\mathrm{Ag}$ heterodimers nanostructures present a displacement in the values associated with the potential formation and reduction of metal oxides. Based on this behavior, it can be deduced that the two systems have different electrochemical characteristics. It is important to note that the presence of $\alpha-\mathrm{Fe}_{2} \mathrm{O}_{3}$ increases the region where monolayers of oxides are formed. It has been reported that the position of hydrogen adsorption/desorption peak and the oxygen reduction peak is proportional to the nanoparticle size [27]. Nevertheless, the synthesis of monometallic $(\mathrm{Ag})$ and bimetallic $\left(\alpha-\mathrm{Fe}_{2} \mathrm{O}_{3}-\mathrm{Ag}\right)$ nanoparticles was carried out analogously under the same conditions, such that very similar particle sizes were obtained. In this 


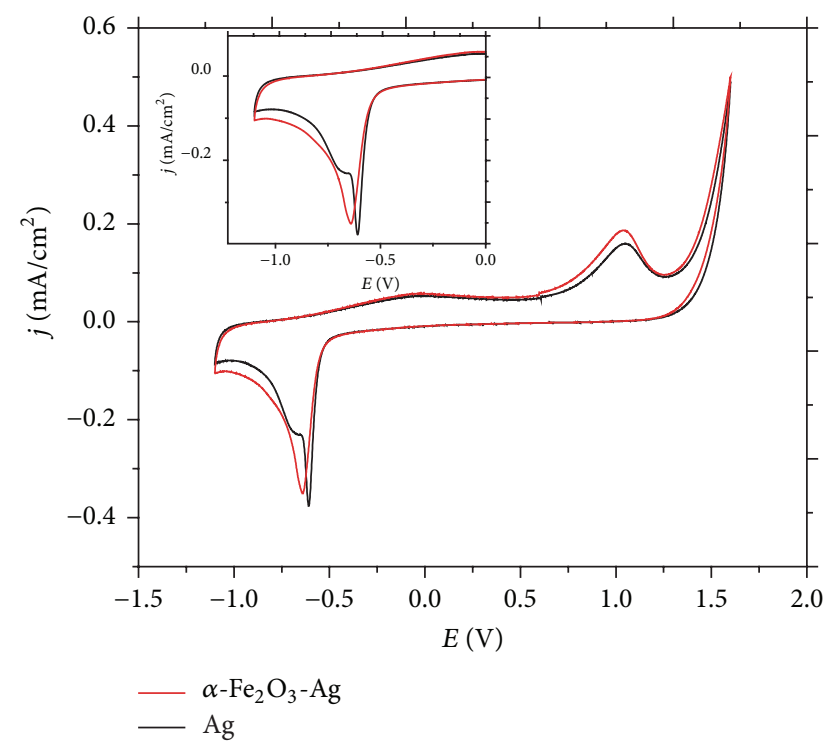

FIgURE 5: Cyclic voltammograms of the $\alpha-\mathrm{Fe}_{2} \mathrm{O}_{3}-\mathrm{Ag}$ and $\mathrm{Ag}$ nanoparticles in acid medium employed a solution of $\mathrm{H}_{2} \mathrm{SO}_{4}$ $(0.5 \mathrm{M})$. Scan rate $50 \mathrm{mV} \mathrm{s}^{-1}$ at $25^{\circ} \mathrm{C}$ in presence of $\mathrm{N}_{2}$.

sense, the electrochemical comparison of both systems is considerably accurate. Hence, through this technique, it is possible to determine the electrochemical behavior of the monometallic (Ag) nanoparticles and the influence of hematite in the processes of oxidation and reduction.

\section{Conclusions}

The synthesis of $\alpha-\mathrm{Fe}_{2} \mathrm{O}_{3}$-Ag dumbbell-like nanostructures or heterodimers was performed using a novel and simplified route, in which factors as temperature and $\mathrm{pH}$ of the aqueous solution were constant. It was observed that the formation of these nanostructures is favored by factors such as compensation charges generated by $\mathrm{Ag}$ and $\alpha-\mathrm{Fe}_{2} \mathrm{O}_{3}$ particles, which are derived from the structure type and the active sites of these entities. Moreover, structural characterization of the bimetallic system was carried out mainly by TEM techniques, and corroborated by modeling and simulation of HRTEM images. However, the different species of iron oxides have a large number of similarities as lattice parameters, $d$ spacings, and chemical composition. Thus, an analysis by Raman spectroscopy was conducted, in order to specify the type of iron oxide present in the bimetallic system. This study confirms that the majority phase of this system is hematite. Nevertheless, some traces of maghemite and magnetite were identified. On the other hand, the electrochemical characterization reveals that this kind of bimetallic nanostructure offers potential catalytic applications, given their particular behavior observed in the studies of cyclic voltammetry. It should be noted that the oxidation and reduction potentials are very well defined and hence a significant catalytic activity could be expected.

\section{Conflict of Interests}

The authors declare that there is no conflict of interests regarding the publication of this paper.

\section{References}

[1] X. Song, X. Luo, Q. Zhang, A. Zhu, L. Ji, and C. Yan, "Preparation and characterization of biofunctionalized chitosan/ $/ \mathrm{Fe}_{3} \mathrm{O}_{4}$ magnetic nanoparticles for application in liver magnetic resonance imaging," Journal of Magnetism and Magnetic Materials, vol. 388, pp. 116-122, 2015.

[2] J. He, M. Huang, D. Wang, Z. Zhang, and G. Li, "Magnetic separation techniques in sample preparation for biological analysis: a review," Journal of Pharmaceutical and Biomedical Analysis, vol. 101, pp. 84-101, 2014.

[3] K. Zangeneh Kamali, P. Alagarsamy, N. M. Huang, B. H. Ong, and H. N. Lim, "Hematite nanoparticles-modified electrode based electrochemical sensing platform for dopamine," The Scientific World Journal, vol. 2014, Article ID 396135, 13 pages, 2014.

[4] K. U. Suganya, K. Govindaraju, V. G. Kumar et al., "Size controlled biogenic silver nanoparticles as antibacterial agent against isolates from HIV infected patients," Spectrochimica Acta Part A: Molecular and Biomolecular Spectroscopy, vol. 144, pp. 266-272, 2015.

[5] N. Khatoon, A. Mishra, H. Alam, N. Manzoor, and M. Sardar, "Biosynthesis, characterization, and antifungal activity of the silver nanoparticles against pathogenic Candida species," BioNanoScience, vol. 5, no. 2, pp. 65-74, 2015.

[6] R. Manikandan, B. Manikandan, T. Raman et al., "Biosynthesis of silver nanoparticles using ethanolic petals extract of Rosa indica and characterization of its antibacterial, anticancer and anti-inflammatory activities," Spectrochimica Acta Part A: Molecular and Biomolecular Spectroscopy, vol. 138, pp. 120-129, 2015.

[7] D. C. M. Ferreira, G. F. Giordano, C. C. D. S. P. Soares et al., "Optical paper-based sensor for ascorbic acid quantification using silver nanoparticles," Talanta, vol. 141, pp. 188-194, 2015.

[8] D. Ramimoghadam, S. Bagheri, and S. B. A. Hamid, "Progress in electrochemical synthesis of magnetic iron oxide nanoparticles," Journal of Magnetism and Magnetic Materials, vol. 368, pp. 207-229, 2014.

[9] R. Frison, G. Cernuto, A. Cervellino et al., "Magnetitemaghemite nanoparticles in the 5-15 $\mathrm{nm}$ range: correlating the core-shell composition and the surface structure to the magnetic properties. A total scattering study," Chemistry of Materials, vol. 25, no. 23, pp. 4820-4827, 2013.

[10] P. I. P. Soares, A. M. R. Alves, L. C. J. Pereira et al., "Effects of surfactants on the magnetic properties of iron oxide colloids," Journal of Colloid and Interface Science, vol. 419, pp. 46-51, 2014.

[11] L. Shen, Y. Qiao, Y. Guo et al., "Facile co-precipitation synthesis of shape-controlled magnetite nanoparticles," Ceramics International, vol. 40, no. 1, pp. 1519-1524, 2014.

[12] M. Abbas, B. Parvatheeswara Rao, S. M. Naga, M. Takahashi, and C. Kim, "Synthesis of high magnetization hydrophilic magnetite $\left(\mathrm{Fe}_{3} \mathrm{O}_{4}\right)$ nanoparticles in single reaction-surfactantless polyol process," Ceramics International, vol. 39, no. 7, pp. 76057611, 2013. 
[13] F. Rahmaniyan, A. Shamel, and A. Shafaghatlonbar, "Evaluation of biologically synthesized silver nanoparticles by the bioreduction method," Synthesis and Reactivity in Inorganic, MetalOrganic, and Nano-Metal Chemistry, vol. 45, no. 10, pp. 14951500, 2015.

[14] M.-Y. Wang, T. Shen, M. Wang, D.-E. Zhang, Z.-W. Tong, and J. Chen, "One-pot synthesis of $\alpha-\mathrm{Fe}_{2} \mathrm{O}_{3}$ nanoparticles-decorated reduced graphene oxide for efficient nonenzymatic $\mathrm{H}_{2} \mathrm{O}_{2}$ biosensor," Sensors and Actuators, B: Chemical, vol. 190, pp. 645-650, 2014.

[15] H.-L. Lien, D. W. Elliott, Y.-P. Sun, and W.-X. Zhang, "Recent progress in zero-valent iron nanoparticles for groundwater remediation," Journal of Environmental Engineering and Management, vol. 16, no. 6, pp. 371-380, 2006.

[16] A. Ruíz-Baltazar, R. Esparza, G. Rosas, and R. Pérez, "Effect of the surfactant on the growth and oxidation of iron nanoparticles," Journal of Nanomaterials, vol. 2015, Article ID 240948, 8 pages, 2015.

[17] R. Esparza, G. Rosas, M. López Fuentes et al., "Synthesis of gold nanoparticles with different atomistic structural characteristics," Materials Characterization, vol. 58, no. 8-9, pp. 694-700, 2007.

[18] R. Long, S. Zhou, B. J. Wiley, and Y. Xiong, "Oxidative etching for controlled synthesis of metal nanocrystals: atomic addition and subtraction," Chemical Society Reviews, vol. 43, no. 17, pp. 6288-6310, 2014.

[19] S. Chandrasekaran, S. H. Hur, E. J. Kim et al., "Highlyordered maghemite/reduced graphene oxide nanocomposites for high-performance photoelectrochemical water splitting," RSC Advances, vol. 5, no. 37, pp. 29159-29166, 2015.

[20] W. S. Peternele, V. Monge Fuentes, M. L. Fascineli et al., "Experimental investigation of the coprecipitation method: an approach to obtain magnetite and maghemite nanoparticles with improved properties," Journal of Nanomaterials, vol. 2014, Article ID 682985, 10 pages, 2014.

[21] J. B. Lee, H. J. Kim, J. Lužnik et al., "Synthesis and magnetic properties of hematite particles in a 'nanomedusa' morphology," Journal of Nanomaterials, vol. 2014, Article ID 902968, 9 pages, 2014.

[22] W. Kim, C.-Y. Suh, S.-W. Cho et al., "A new method for the identification and quantification of magnetite-maghemite mixture using conventional X-ray diffraction technique," Talanta, vol. 94, pp. 348-352, 2012.

[23] A. M. Jubb and H. C. Allen, "Vibrational spectroscopic characterization of hematite, maghemite, and magnetite thin films produced by vapor deposition," ACS Applied Materials and Interfaces, vol. 2, no. 10, pp. 2804-2812, 2010.

[24] O. Moscoso-Londoño, D. Muraca, P. Tancredi, C. CosioCastañeda, K. R. Pirota, and L. M. Socolovsky, "Physicochemical studies of complex silver-magnetite nanoheterodimers with controlled morphology," Journal of Physical Chemistry C, vol. 118, no. 24, pp. 13168-13176, 2014.

[25] E. Giorgetti, P. Marsili, F. Giammanco, S. Trigari, C. Gellini, and M. Muniz-Miranda, "Ag nanoparticles obtained by pulsed laser ablation in water: surface properties and SERS activity," Journal of Raman Spectroscopy, vol. 46, no. 5, pp. 462-469, 2015.

[26] T. Gong, Y. Zhu, J. Zhang, W. Ren, J. Quan, and N. Wang, "Study on surface-enhanced Raman scattering substrates structured with hybrid Ag nanoparticles and few-layer graphene," Carbon, vol. 87, pp. 385-394, 2015.
[27] B. Escobar Morales, S. A. Gamboa, U. Pal et al., "Synthesis and characterization of colloidal platinum nanoparticles for electrochemical applications," International Journal of Hydrogen Energy, vol. 35, no. 9, pp. 4215-4221, 2010. 

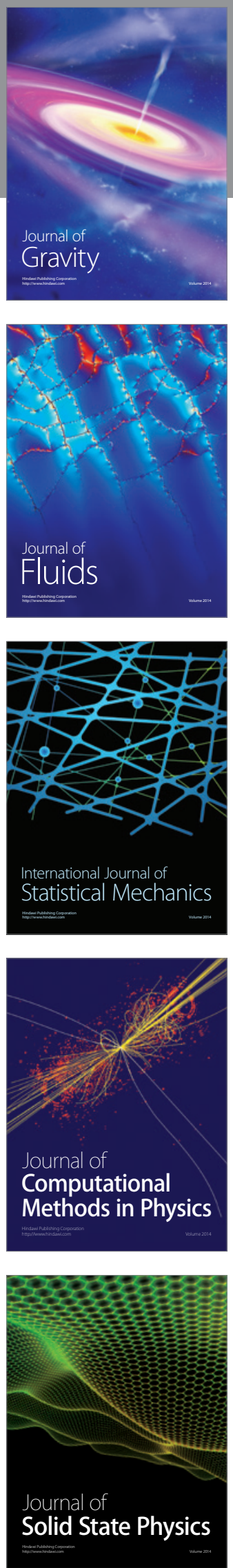

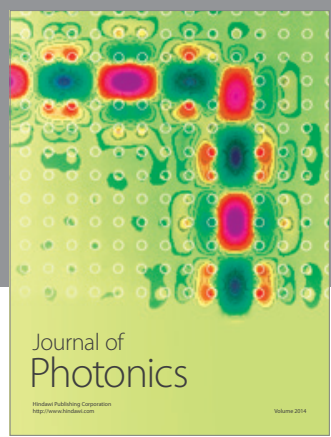

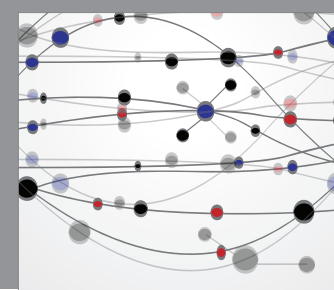

The Scientific World Journal

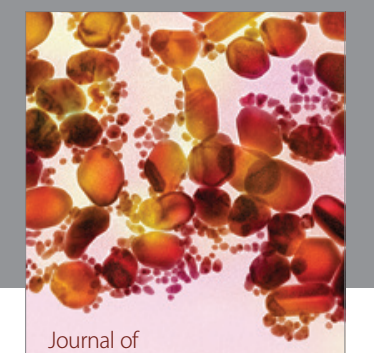

Soft Matter
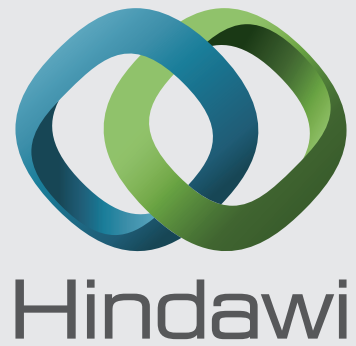

Submit your manuscripts at

http://www.hindawi.com
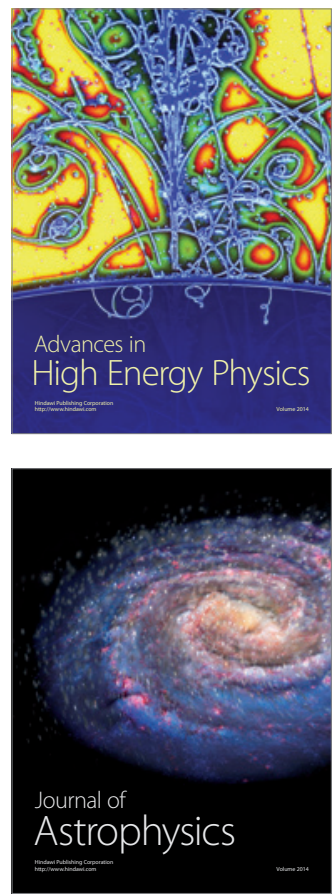
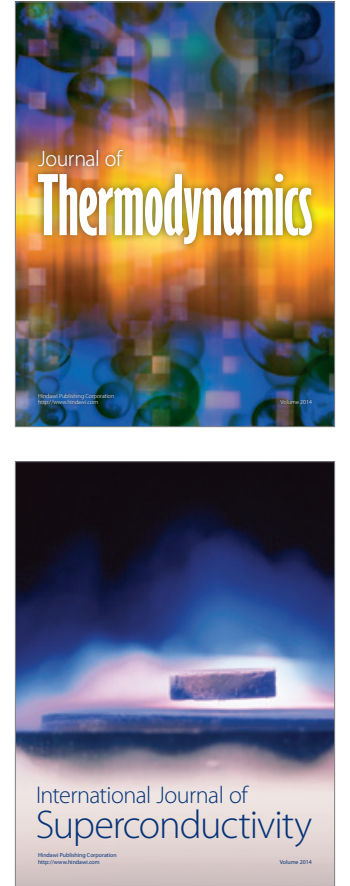
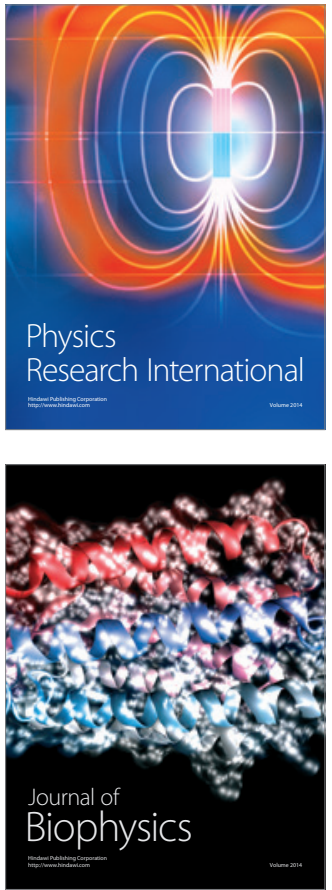
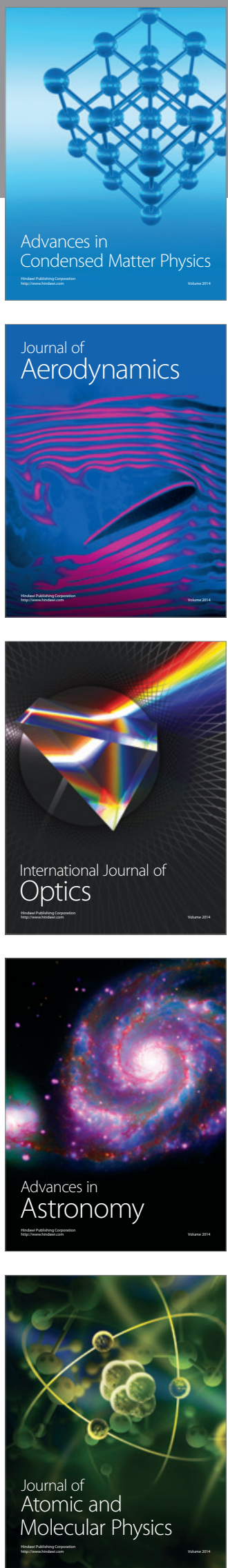